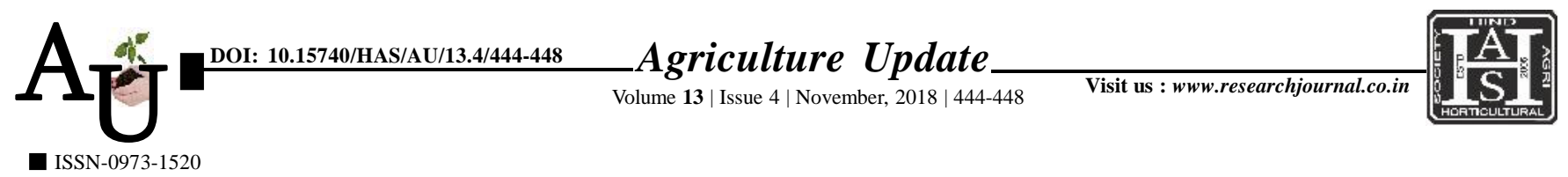

\title{
Research Article: Effect of demonstration on farmer buying behaviour in Shrirampur and Nagar tahasil
}

\author{
A.K. Kokare and A.S. Kshirsagar
}

Article Chronicle :

Received :

24.08.2018;

Revised :

29.09.2018;

Accepted :

15.10.2018

\section{KeY WoRDS :}

Water soluble fertilizer,

Demonstration, Farmer buying behaviour
SUMMARY : This study was conducted between July 2018. We visited to the 100 farmer of Shrirampur tahasil and 100 famer of Nagar tahasil for demo of water soluble fertilizer. We select vedant fertilizer two product (soil booster) and (NPK 19:19:19) for demo. We give demo of soil booster on date 5 July 2018 and NPK 19:19:19 on date 20 July 2018 in Shrirampur tahasil and demo of soil booster on date 8 July 2018 and NPK 19:19:19 on date 23 July 218 in Nagar tahasil. We recorded of observation of farmer buying behaviours of fertilizer. Water soluble fertilizer gives good result on crop after few day of demonstration most farmers observed healthy development of crop so farmer purchase nutrilex water soluble fertilizer. Soil booster used to all crop at time of plantation. It help to soil boost micronutrient available and (NPK 19:19:19) use second stage of maturity also 19:19:19 balance macro nutrient. It useful for primary growth of nutrient. Due to demonstration we observed rise in the sale of nutrilex water soluble product. Demonstration activity was adopted by almost all firms followed by exhibitions and premiums and gifts. Field demonstration was adopted by various companies because unless the farmer sees the crop in the field he will not believe in the product. Hence, demonstrations played a major role in the promotional activities conducted by the various companies (Bansal et al., 2013).

How to cite this article : Kokare, A.K. and Kshirsagar, A.S. (2018). Effect of demonstration on farmer buying behaviour in Shrirampur and Nagar tahasil. Agric. Update, 13(4): 444-448; DOI : 10.15740/HAS/AU/13.4/444448. Copyright@2018: Hind Agri-Horticultural Society.
Author for correspondence :

\section{A.K. Kokare}

College of Agriculture

Business Management, Loni, Ahmednagar

(M.S.) India

Email:7amitkokare@ gmail.com

See end of the article for authors' affiliations 